\title{
REFLEXÕES SOBRE O ENSINO DE GEOGRAFIA PARA ALUNOS COM DEFICIÊNCIA EM SALA MULTISSERIALIZADA
}

\author{
REFLEXIONES SOBRE LA ENSEÑANZA DE LA GEOGRAFÍA \\ A ESTUDIANTES CON DISCAPACIDADES EN UNA SALA \\ MULTISERIALIZADA
}

\author{
Ícaro Santos Rocha ${ }^{1}$ \\ Dulce Pereira dos Santos ${ }^{2}$
}

\begin{abstract}
RESUMO
$\mathrm{O}$ ensino em salas multisseriadas surgiu como uma maneira de proporcionar o ensino aos indivíduos que por muito tempo foram excluídos do acesso à escola, sendo, portanto, um aspecto ligado ao processo de segregação social que existe predominantemente em países subdesenvolvidos. Neste contexto, a quantidade reduzida de alunos presentes faz com que surjam classes multisseriadas, unindo alunos de duas ou mais turmas diferentes. Tal situação leva o professor a lidar com a questão de ter que ministrar conteúdos diferentes em turmas com grande diversidade de níveis de aprendizagem, tanto pelo aspecto de haver alunos em séries diferentes, quanto pelo fator cognitivo. Vale ressaltar que a temática da educação inclusiva não é abordada apenas na questão da multisserialização e da educação do campo, mas também no ensino de pessoas com deficiência, que possuem as suas especificidades e que estão no ensino regular não apenas para a promoção da sua socialização, mas também para aprender como todos os outros alunos. Sendo assim, ocorre a necessidade de observar a educação do campo, a multisserialização e a educação inclusiva com as suas peculiaridades, visando o estabelecimento de um processo de ensino-aprendizagem que preze pela diversidade e pela equidade, onde todos possam aprender. No que se refere à geografia escolar, o professor deve garantir que os alunos possam compreender os conteúdos relacionados à disciplina prezando sempre pelo respeito ao tempo do aluno aprender, utilizando recursos que facilitem o seu aprendizado, além de construir conhecimentos relacionados ao espaço de vivência do discente e o seu papel como cidadão. Portanto, o respectivo trabalho tem como objetivo fazer considerações sobre o ensino de alunos com deficiência e os desafios enfrentados para o seu desenvolvimento no contexto de uma turma multisseriada em Miralta, distrito de Montes Claros-MG. A metodologia desta produção se estabelece por meio de levantamentos bibliográficos, a empiria por meio do exercício da docência e entrevistas realizadas junto a professora de apoio da turma. Apesar dos fatores que contribuem para uma melhor compreensão dos conteúdos, muitos obstáculos

\footnotetext{
${ }^{1}$ Especialista, Secretaria de Estado da Educação, Professor de Geografia da Educação Básica. E-mail: icaro.s@outlook.com.br

${ }^{1}$ Professora Dra. Curso de Geografia da Universidade Estadual de Montes Claros - Unimontes.
} 
existem para que o processo de ensino-aprendizagem possa ser mais efetivo no local em questão.

Palavras-chave: Multisserialização. Inclusão. Geografia.

\begin{abstract}
La enseñanza en clase multinivel surgió como una forma de proporcionar la educación a las personas que durante mucho tiempo fueron excluidas del acceso a la escuela, por lo que es un aspecto vinculado al proceso de segregación social que existe predominantemente en los países subdesarrollados. En ese contexto, el número reducido de estudiantes presentes conduce a la aparición de clases de varios niveles, uniendo a estudiantes de dos o más niveles diferentes. Esta situación lleva el maestro a enseñar a la vez diferentes contenidos en clases con una gran diversidad de niveles de aprendizaje, tanto por el aspecto de tener estudiantes en diferentes estadios, como por el factor cognitivo. Vale la pena mencionar que el tema de la educación inclusiva no solo se aborda en el tema de multiniveles y la educación rural, sino también en la enseñanza de las personas con discapacidad, que poseen sus especificidades y que están en educación regular no solo para promover su socialización, pero también para aprender como todos los demás estudiantes. En esa línea, es necesario observar la educación rural, la multiniveles y la educación inclusiva con sus peculiaridades, con el objetivo de establecer un proceso de enseñanza-aprendizaje que valore la diversidad y la equidad, donde todos puedan aprender. Con respecto a la geografía escolar, el maestro debe asegurarse de que los estudiantes puedan comprender los contenidos relacionados con la asignatura, siempre respetando el tiempo de aprendizaje del alumno, utilizando recursos que faciliten su aprendizaje, además de construir conocimiento relacionado con el espacio donde vive el alumno y su papel como ciudadano. Eso puesto, esto trabajo presenta consideraciones sobre la enseñanza de estudiantes con discapacidades y los desafíos que enfrentan para su desarrollo en el contexto de una clase multinivel en Miralta, región perteneciente a la ciudad de Montes Claros-MG. La metodología de esta producción se establece mediante recogida bibliográfica, el empirismo a través del ejercicio de la enseñanza y las entrevistas realizadas con el maestro de apoyo de la clase. A pesar de los factores que contribuyen a una mejor comprensión de los contenidos, existen muchos obstáculos para que el proceso de enseñanza-aprendizaje pueda ser más efectivo en el lugar en cuestión.
\end{abstract}

Palabras clave: Multiniveles. Inclusión. Geografía

\title{
INTRODUÇÃO
}

A educação é um direito que deve ser estabelecido de maneira universal, de modo que possa abranger todos os indivíduos. A Constituição Federal da República Federativa do Brasil (1988) coloca a educação como um direito de todos, tendo como objetivo o pleno desenvolvimento da pessoa, a sua preparação para exercer o seu papel de cidadão, bem como a qualificação para o trabalho. Ainda conforme a Constituição, o acesso à educação deve ser garantido de maneira igualitária, para que todos possam ter condições de acesso a tal serviço em seus variados níveis (séries iniciais, fundamental, médio e superior), garantindo também a permanência do aluno, independente das suas características, já que a oferta de atendimento educacional especializado também deve ocorrer preferencialmente dentro do ensino regular.

Neste sentido, a perspectiva da inclusão através da educação é primordial para ofertar o acesso a esse serviço básico a todas as pessoas, independente das especificidades presentes 
em determinados locais. Em alguns casos, apesar do estereótipo de classes abarrotadas de alunos que é presente em várias escolas brasileiras, existem locais que em virtude da pequena quantidade de alunos para cada série, acaba sofrendo com a multisserialização das turmas, sendo colocados alunos de séries diferentes em uma mesma classe, levando o professor a lidar não apenas com o processo de ensino-aprendizagem de alunos de séries diferentes em um mesmo horário, mas também com a própria diversidade no aspecto cognitivo existente na sala de aula. No caso específico da geografia, o professor acaba tendo que levar em consideração como expor os conteúdos referentes à disciplina para alunos de séries diferentes, respeitando às peculiaridades do local em que a escola está inserida, a experiência de vida dos alunos e a própria diversidade na aprendizagem dos mesmos, principalmente no caso dos alunos com deficiência.

Neste sentido, o trabalho em questão busca realizar um estudo a respeito do ensino de geografia em uma turma multisserializada em Miralta, distrito do município de Montes Claros-MG. Portanto, os objetivos desta produção se baseiam em expor considerações sobre salas multisserializadas e a educação do campo; levantar aspectos referentes à geografia como disciplina escolar e a sua relação com a educação especial; e contextualizar a situação do processo de ensino-aprendizagem de alunos com deficiência em uma turma multisserializada no local, suas peculiaridades e os desafios presentes, sendo que tais informações foram obtidas através da experiência docente e entrevistas com a professora de apoio da turma.

\section{Considerações gerais sobre as salas multisseriadas e a educação no campo}

Ao se tratar das salas multisseriadas, logo se percebe que este tipo de classe possui uma relação profundamente inerente com a realidade de exclusão que é enfrentada pelas populações que residem no espaço rural. Neste contexto, Parente $(2014$, p. 62) expõe que "as escolas multisseriadas nasceram como opção política de atender a uma população historicamente excluída da escola. Tal atraso na oferta educacional é muito mais visível em países em desenvolvimento, como é o caso do Brasil". Portanto, o estabelecimento de salas multisseriadas surge com o objetivo de buscar integrar essas pessoas que passaram muito tempo sem acesso à educação, sendo que tal situação se insere como uma alternativa política para tentar conter o problema da disponibilidade insuficiente de um serviço primordial à sociedade.

A formação de turmas multisseriadas se estabelece justamente pela quantidade reduzida de alunos no que tange a composição de uma classe completa, com estudantes de apenas uma série. Neste sentido, conforme Santos (2017, p. 7) afirma: 
As classes multisseriadas são formadas pelo número reduzido de alunos para cada série, o que a caracteriza como mais do que uma simples classe. Essas turmas reúnem alunos de vários níveis, onde um único professor é responsável pelo ensino e condução do trabalho pedagógico, sendo diferenciada da maioria das escolas urbanas onde as turmas são formadas por séries e cada turma tem o seu próprio professor.

Portanto, percebe-se que ao surgir dentro de um contexto de necessidade, as classes multisseriadas detêm peculiaridades, já que ela concentra alunos de níveis diferentes. Assim, o docente recebe a tarefa de reger os conteúdos referentes às turmas em questão, tendo que proporcionar o processo de ensino-aprendizagem alunos de séries diversas.

No que se diz respeito ao papel docente, dentro do contexto não apenas nas turmas multisseriadas, mas também na educação do campo, uma situação que acaba por contribuir com as dificuldades presentes é falta de laços que o professor detém com o local em que ele exerce a sua profissão. Segundo Hage (2009), essa falta de vínculos diz respeito à origem do docente, já que ele trabalha no espaço rural, mas normalmente não é oriundo do meio em questão. Assim, ao ocorrer o surgimento de oportunidades, o profissional buscará sair das escolas rurais, provocando uma grande rotatividade de profissionais.

Neste contexto, pode-se perceber que em virtude da falta de identificação com o local impede que ocorra maior permanência de profissionais nas escolas. O motivo da ida desses docentes para trabalhar em escolas rurais é a função que esses lugares exercem no papel de facilitadores de inserção de novos professores no mercado de trabalho. Assim, os docentes acabam enfrentando as adversidades que o local pode proporcionar para obter maior experiência na profissão, já que a disponibilidade de trabalho nos ambientes urbanos costuma ser reduzida para docentes em início de carreira. Corroborando com a afirmação realizada, Rodrigues (2009, p. 83) expõe:

É nítido que o meio rural é tido como uma espécie de "porta de entrada" do mercado de trabalho, pois a maioria dos professores começa sua carreira profissional no campo e, como não poderia deixar de ser, em sala multisseriada, uma vez que o meio urbano encontra-se saturado, restando vagas apenas no meio rural. Quem precisa muito do emprego acaba se sujeitando a se deslocar diariamente da cidade para o campo ou, quando isso não é possível, se mudam para a localidade em questão, o que acarreta diversos transtornos, inclusive de ordem financeira.

Outro aspecto que pode se configurar como um obstáculo para o processo de ensinoaprendizagem em classes multisseriadas é referente à dinâmica no momento de elaboração do plano curricular para estas turmas. De acordo com Hage (2014), os professores possuem certa dificuldade na elaboração dos trabalhos pedagógicos quando as classes são multisseriadas por trabalharem com mais séries ao mesmo tempo, além de se depararem com alunos de idades, níveis de aprendizado e interesse diferentes. Os currículos, normalmente são elaborados utilizando o livro didático como principal fonte de consulta, apesar dos riscos da prática. 
Assim, os docentes precisam não só elaborar currículos, mas também avaliações de séries diferentes, gerando ansiedade para a elaboração de um bom trabalho, e confusão simultaneamente. Esta situação se estabelece pela valorização do modelo seriado urbano de ensino que institui a formulação de conteúdos isolados para cada série, impedindo o docente de visualizar a turma, mesmo com as suas especificidades, como um conjunto.

Portanto, ao observar todos os aspectos abordados, percebe-se que o ensino em salas multisseriadas possui uma série de obstáculos que impedem que o mesmo tenha uma maior efetividade, envolvendo não apenas questões relacionadas à elaboração de conteúdos e a prática docente, mas também a falta de identidade que o professor pode possuir com o seu local de trabalho, quando o que está em foco são turmas multisseriadas presentes em escolas localizadas em áreas rurais.

Já no que diz respeito especificamente à educação do campo a situação não é diferente, pois determinados fatores também contribuem para dificultar um processo de ensino-aprendizagem que contribua mais para a assimilação do aluno com o conteúdo que é ministrado. Tal afirmação corrobora com o que é exposto por Lopes (2015), que coloca que essa educação tem como sujeito a população que vive no campo, levando em conta que estas pessoas possuem uma história e uma identidade, sendo que como a educação tem como principal finalidade a formação intelectual social e política do cidadão, prezando as especificidades do aluno dentro do contexto da universalidade do processo educacional.

É imprescindível que o docente tenha consciência que o aluno residente em áreas não urbanas possui uma história, uma cultura, logo uma identidade construída em virtude do meio em que este está inserido, sendo que a construção dos conhecimentos a serem trabalhados em sala de aula deve tomar os cuidados necessários para que sejam construídos da maneira mais adequada possível para o contexto local. Neste sentido, Zeferino (2014, p. 11), afirma:

Portanto, o educador do campo deve ser aquele que contribui com o processo de desenvolvimento para uma aprendizagem de qualidade, construindo conhecimentos a partir da realidade vivida por eles. Por isso, ele deve se adequar a realidade deste povo para trabalhar a aprendizagem por meio de histórias construídas com suas lutas pela igualdade, educação, cultura e dignidade pela vida.

Portanto, ao considerar essa questão, o docente deve estar atento no que diz respeito à elaboração das aulas, para que o conteúdo possa ser assimilado pelo aluno de um modo mais facilitado, levando em consideração o meio em que o mesmo vive e os aspectos materiais e imateriais que envolvem este local, dando ênfase aos valores que se referem à qualidade de vida e a dignidade, aspectos que devem ser inerentes a todos os cidadãos.

Conforme Lopes (2015), muitas vezes os alunos oriundos das áreas rurais são colocados como um povo pouco trabalhador, sem perspectivas e sonhos, sendo que tal forma de preconceito deve ser combatida, por meio de mudanças nas políticas públicas e na 
formação docente, para que o aluno residente em áreas rurais possa ter as suas particularidades não só reconhecidas, mas também respeitadas.

Considerando tal afirmação, entende-se que apesar da necessidade de cuidado por parte do docente, tanto ao elaborar as suas aulas, quanto no que se refere a sua prática em sala de aula, outros aspectos que envolvem políticas públicas e a formação docente também se mostram como entraves ao desenvolvimento de uma educação do campo de maior qualidade. Neste sentido, a necessidade de políticas públicas educacionais mais eficientes e uma formação que contemple com maior ênfase as especificidades da educação do campo se apresentam como fatores primordiais para que ocorra um maior respeito às particularidades dos alunos e o combate a visão estereotipada que têm do morador do campo.

\section{Sobre a Geografia Escolar e o ensino para pessoas com deficiência}

A geografia como disciplina escolar detêm relevante importância no que diz respeito ao entendimento da realidade. Neste contexto, de acordo com os PCNs (1998), a disciplina tem o compromisso de fazer com o que o mundo seja abordado de uma maneira mais compreensível para os alunos, garantindo que os mesmos possam entender a dinâmica do planeta, suas transformações, bem como a relação existente entre o processo histórico da formação das sociedades humanas e a dinâmica da natureza. Assim, o aluno deve perceber a sua posição no mundo, e que as suas ações tanto individuais como coletivas acarretam consequências para si e para a sociedade, fator que deve despertar uma consciência de solidariedade, visando uma melhor realidade para as futuras gerações e contribuindo para a busca de um ensino para a conquista da cidadania brasileira.

Portanto, entende-se que a geografia mostra um papel fundamental para que se estabeleça um ensino que coloque não apenas o aluno em uma condição de protagonista do processo de ensino-aprendizagem, mas também tem o intuito de inseri-lo como figura central na condição de cidadão, através de uma busca por evidenciar que as suas ações refletem no local que o circunda, já que o mesmo é um ser que se encontra interligado à natureza e à sociedade. Assim, entende-se que a geografia como disciplina escolar detém importante função ao ser responsável por proporcionar um processo de ensino-aprendizagem que enfatize não apenas a assimilação dos conceitos e conteúdos propostos, mas a correlação de tais atributos com a realidade que rodeia o discente, estimulando-o a desenvolver a consciência de que ele é capaz de transformar o meio em que está inserido.

Na Base Nacional Comum Curricular (2015), o ensino de geografia é fundamental para a compreensão do mundo vivido, contribuindo assim com a construção da identidade. Ainda conforme tal documento, o aluno precisa ser estimulado a pensar espacialmente para 
que possa realizar uma leitura do local em que vivem, para que assim possam desenvolver o que é citado como "raciocínio geográfico" 3 .

Ao considerar que a geografia tem papel importante ao buscar colocar o aluno na condição de protagonista em seu papel de agente transformador da sociedade, entende-se que a disciplina em questão possui caráter relevante ao deter um caráter de emancipação do aluno por meio da abordagem da política em seus conteúdos. Neste contexto, Silveira (2011) expõe que é necessário resgatar o caráter emancipatório da educação para que ocorra uma mudança cultural dela, sendo importante que os professores estejam conscientes e motivados no que tange a tal transformação, sendo necessário reconstruir a educação nas abordagens, técnicas e na própria emoção de ensinar. Sendo assim, cabe a geografia incentivar propostas que sejam alternativas aos "raciocínios geográficos" generalizadores, proporcionando aos cidadãos na escola a possibilidade de compreender os problemas presentes no mundo, o que leva a pensar a própria questão educacional.

Quanto ao ensino de geografia no contexto da educação inclusiva, a premissa de que é necessário compreender as especificidades de cada aluno é primordial, já que dentro da sala de aula a pluralidade se faz presente, pois existem alunos com níveis de aprendizado diversos. Sendo assim, cabe ao professor ter a sensibilidade de entender esta situação e garantir que cada estudante consiga assimilar os conhecimentos referentes à disciplina de acordo com o seu tempo de aprendizagem. Tal afirmação corrobora com o que é evidenciado por Sampaio (2011, p. 51):

Outra questão que os professores devem atentar é para o tempo de aprender, pois ter o tempo de aprendizagem respeitado faz parte da inclusão e isso significa vencer preconceitos, pois aquele que demora a aprender também aprende. Não aceitar a definição de especial no sentido de "deficiente", no sentido de instituições particulares quanto à forma educativa, no sentido de educação menor, irrelevante, incompleta.

O respeito ao tempo de aprendizagem do aluno é de grande importância para o desenvolvimento dele, pois assim, todos têm a possibilidade de aprender independente das limitações que possuam. Para que esse processo ocorra, é importante entender que o processo de ensino-aprendizagem deva atender a todos e que nesse sentido, a educação especial no contexto da escola inclusiva não seja depreciada, sendo o respeito às diferenças de aprendizagem um aspecto primordial.

Entretanto, para que esse processo possa ser viabilizado de maneira satisfatória, existem certas questões que se configuram como um obstáculo que impedem que o processo

\footnotetext{
${ }^{3}$ Conforme a BNCC, o "raciocínio geográfico" diz respeito à forma de "compreender aspectos fundamentais da realidade: a localização e a distribuição dos fatos e fenômenos na superfície terrestre, o ordenamento territorial, as conexões existentes entre componentes físico-naturais e as ações antrópicas". (BRASIL 2019, p. 359). De acordo com o respectivo documento, tal concepção está presente em propostas curriculares de outros países, como Austrália, Chile, Estados Unidos, Portugal e Reino Unido.
} 
de ensino-aprendizagem seja mais dinâmico. De acordo com Sampaio (2011), a falta de materiais específicos que atendam a todos os alunos e auxiliem o professor é um problema, contribuindo assim para uma menor eficiência no aprendizado de todos os estudantes, considerando que não só a construção do conhecimento, mas a sala de aula também deve ser inclusiva, tendo à disposição recursos que possam atender a todos, justificando a sua função social e política. Outro fator a ser levantado diz respeito especificamente ao docente, sendo que para que o ensino de geografia possa contemplar as características dos alunos, é necessário que o professor tenha estímulos desde o seu processo de formação, em que ele seja incentivado a buscar uma inovação e valorizar as suas práticas, produzindo um ensino mais dinâmico, ao invés de ser baseado simplesmente na repetição de conhecimentos distantes da realidade dos alunos.

Considerando tais aspectos, é perceptível que além da necessidade de recursos didáticos adequados, a própria formação docente deve preparar professores para lidar com a diversidade presente no ambiente escolar, para que assim, ocorra o estabelecimento de uma escola inclusiva, no sentido de uma prática docente que contemple todos os alunos na compreensão dos conteúdos referentes à geografia como disciplina escolar.

\section{Contextualização sobre o ensino de geografia para alunos com deficiência em uma sala multisseriada numa escola de área rural}

O estudo em questão foi realizado em uma escola da rede pública estadual localizada em Miralta, distrito pertencente ao município de Montes Claros - MG. Para realizar a pesquisa, foi selecionada uma sala que possui duas turmas que utilizam o mesmo ambiente, no caso, uma sala multisseriada. A sala em questão envolve turmas do sexto e sétimo ano da escola, sendo que tal situação foi estabelecida em virtude da quantidade de alunos presentes em cada turma, já que o sexto ano possui sete alunos, enquanto o sétimo ano tem doze discentes. Devido à quantidade reduzida de estudantes, o estado orientou o estabelecimento de uma união, concretizando assim a multisserialização das turmas, sendo o único caso ocorrido na escola.

Apesar da ocorrência desse processo, é importante ressaltar que apesar da menor quantidade de alunos nas duas turmas, consequências foram geradas no que diz respeito ao processo de ensino-aprendizagem dos alunos. Tal fator se concretiza por meio da diversidade presente na sala, no que diz respeito especificamente à questão dos alunos com deficiência presentes nas turmas. Dos dezenove alunos da sala, há um aluno com microcefalia e déficit de atenção (aluno 1) e uma aluna com epilepsia e paralisia cerebral (aluna 2), sendo que um aluno pertence ao sexto ano e a outra aluna está no sétimo ano. Esses dois alunos recebem o 
auxílio da professora de apoio, que trabalha com esses alunos os conteúdos estudados em sala de aula. Neste contexto, a referida professora precisa trabalhar conteúdos diferentes, de séries distintas com esses alunos utilizando maneiras diferentes, em virtude das especificidades de cada aluno.

Vale ressaltar que os alunos citados possuem o direito do auxílio de um professor de apoio na sala de aula. Entretanto, existem outros alunos que também possuem características específicas e que não gozam do mesmo direito, mas que também acabam pedindo o apoio da respectiva professora, gerando um maior trabalho para ela. Nesse caso, há um aluno que possui dislexia e déficit de atenção (aluno 3) do sétimo ano e outro aluno que apesar de estar no sexto ano, chegou a tal série com profundas dificuldades em leitura e escrita (aluno 4). No que se refere a este último aluno, a leitura se limita a algumas frases e no caso da escrita, ele apenas escreve o seu primeiro nome sem nenhuma ajuda.

O aluno 1 apesar das suas limitações, consegue participar ativamente das aulas com o auxílio da professora de apoio e obtém bom aproveitamento em atividades e avaliações, conseguindo em certas ocasiões se destacar em relação aos demais alunos da sua turma. No caso da aluna 2, o processo de ensino-aprendizagem é mais lento, sendo realizadas atividades em que a alfabetização é trabalhada com maior enfoque, devido o comprometimento das suas funções cognitivas e motoras.

Em conversa com a diretoria da escola, foi relatado que o desenvolvimento intelectual do aluno 4 tem sido observado pelos docentes desde as séries iniciais e foi percebido por todos profissionais que trabalharam como docentes deste aluno a dificuldade que ele possuía em assimilar os conteúdos trabalhados no que tange à alfabetização. Por conta dessas dificuldades, os pais do aluno em questão já foram chamados à escola e orientados a levarem o filho para realizar exames com o intuito de verificar se o discente detém alguma particularidade no que tange à sua aprendizagem. Apesar da orientação feita pela escola, o fato não foi realizado pelos pais, contribuindo para a permanência do aluno na escola em tais condições.

No que se refere aos docentes, há uma dupla dificuldade: a necessidade de trabalhar dois conteúdos de séries distintas em um curto período, e a elaboração de várias atividades que possam contemplar os diversos níveis de aprendizagem apresentados pelos alunos das duas turmas. A questão da aprendizagem ainda é afetada por outros aspectos, como a indisciplina e o desinteresse por parte de alguns alunos. Através da convivência com a turma, além de conversas e uma entrevista com a professora de apoio, foi possível perceber que os alunos do sexto ano são mais desinteressados. Conforme a respectiva professora, os alunos do sétimo ano são mais dedicados em realizar as atividades que são propostas, apesar das 
dificuldades que os dois alunos que ela acompanha dessa série possuem. Já no sexto ano, além do desinteresse ser latente, a indisciplina também prejudica o andamento das aulas, já que alguns alunos conversam e costumam fazer brincadeiras, além de um comportamento desrespeitoso com o professor. Tais atitudes consequentemente, atrapalham o processo de ensino-aprendizagem da turma, atingindo todos os alunos. Neste contexto dá-se ênfase aos alunos que possuem alguma deficiência, já que os aspectos citados se constituem como mais um obstáculo para a construção de conhecimentos com estes alunos.

A escola em questão possui uma sala de recursos multifuncionais, que realiza atividades com os alunos do $6^{\circ}$ e $7^{\circ}$ anos, assim como alunos de outras turmas que também estão matriculados para participar dos trabalhos propostos por este local. Conforme as Diretrizes Nacionais para a Educação Especial na Educação Básica (2001), a sala de recursos é um local destinado a suplementar ou complementar o atendimento do aluno com deficiência que é realizado nas classes comuns, utilizando de recursos pedagógicos que sejam adequados às suas especificidades. Sendo assim, a sala de recursos atua como um meio auxiliador do desenvolvimento do aluno, sendo que este processo não ocorre apenas dentro da sala de aula.

Entretanto, de acordo com o Guia de Orientação da Educação Especial na rede estadual de ensino de Minas Gerais (2013), afirma que as atividades realizadas na sala de recursos não devem ser confundidas com aulas de reforço ou atendimentos clínicos, sendo que o local também não deve ser confundido com um espaço de socialização. O local é voltado para a realização de atividades que buscam o desenvolvimento cognitivo, ensino de linguagens e códigos para a comunicação, enriquecimento curricular, ajudas técnicas e tecnologias assistivas.

Dos quatro alunos que recebem o auxílio direto ou indireto da professora de apoio, três estão matriculados na sala de recursos, sendo que o único aluno não matriculado é o aluno 4. Apesar da sala de recursos constituir um aspecto de relevância para o desenvolvimento cognitivo do aluno, nem todos os alunos da turma a utilizam, mesmo possuindo o direito ao seu uso. De acordo com a professora de apoio, apenas o aluno 1 frequenta a sala de recursos, sendo que a aluna 2 não vai ao local sob a justificativa que os medicamentos que ela utiliza afetam o seu sono, impedindo que ela consiga acordar a tempo para as atividades no contraturno. No caso do aluno 3, ele não consegue fazer o uso da sala de recursos devido ao transporte escolar. Neste caso, o estudante em questão mora fora do distrito de Miralta, e o transporte escolar passa no seu local de residência apenas no turno vespertino.

Outro fator a ser considerado diz respeito à frequência desses alunos durante as aulas regulares. Dos quatro alunos citados, três deles vão assiduamente às aulas, sendo a aluna 2 exceção neste aspecto. No decorrer do período letivo, a professora de apoio expôs a situação 
durante as reuniões do corpo docente com a direção da escola, sendo que aspecto mais preocupante dessa situação é a regressão do desenvolvimento intelectual e cognitivo da estudante em questão conquistados por meio do processo de ensino-aprendizagem em sala de aula.

No que se refere ao processo de ensino-aprendizagem dos alunos que precisam do auxílio da professora de apoio, o uso de recursos audiovisuais (imagens, vídeos, sons) contribuem para uma maior assimilação dos conteúdos referentes à geografia. A explicação oral também se insere como um recurso facilitador, sendo que todos os aspectos citados são utilizados nas aulas de geografia, buscando articular o ensino dos conteúdos propostos com uma linguagem que contribua com a assimilação dos alunos e a tentativa do uso de exemplos que sejam mais próximos do seu cotidiano.

Tais recursos têm certa eficácia por facilitar o aprendizado de quase todos os alunos, independente das limitações que os alunos possam deter, sendo que este fator foi também enfatizado pela professora de apoio durante a entrevista. A única exceção se refere à aluna que possui paralisia cerebral que o processo de aprendizagem é mais lento em virtude das suas condições cognitivas e motoras. Além do uso de recursos que busquem facilitar o processo de ensino-aprendizagem, a elaboração de atividades diferenciadas é crucial, tendo a consciência de que existem alunos com níveis de aprendizagem extremamente diversos. Portanto, a realização de atividades que sejam condizentes à aprendizagem do aluno é fundamental, buscando contemplar aspectos específicos que devem ser trabalhados com maior aprofundamento, como a leitura, escrita, interpretação, entre outros aspectos.

\section{Considerações Finais}

Ao se tratar do processo de ensino-aprendizagem em salas multisseriadas, é possível perceber que o surgimento desse aspecto surgiu com uma proposta de incluir e proporcionar o ensino para aquelas pessoas que ficaram segregadas e não tiveram oportunidades em períodos anteriores das suas vidas. Porém, ao lecionar em uma turma nesta condição, é necessário ter a consciência das grandes disparidades existentes entre os alunos que compõem a sala, já que existem pessoas de séries diferentes e níveis de aprendizagem diversos, sendo indispensável ao professor a ciência e o respeito à diversidade existente no ambiente, bem como as particularidades do local, quando se trata especificamente do ensino em salas multisseriadas no contexto da educação do campo.

No que se refere à geografia escolar, a disciplina em questão detém o importante papel de instigar o aluno a desenvolver uma consciência mais crítica a respeito da realidade que o circunda, sendo imprescindível que o mesmo consiga despertar a perspectiva de que ele é um 
sujeito ativo e que ajuda na construção do espaço ao seu redor, ou seja, um agente transformador da sua própria realidade e daqueles ao seu redor. Considerando a geografia escolar no local que serviu como objeto de estudo do presente trabalho, foi percebido tanto pela convivência, quanto pelas declarações da professora de apoio, que o uso de recursos audiovisuais, a oralidade e o emprego de atividades diferenciadas que estejam de acordo com o nível de aprendizagem dos alunos contribuem para o processo de ensino-aprendizagem dos mesmos, articulando a percepção das paisagens dos locais estudados, com as suas dinâmicas.

Todavia, existe uma série de empecilhos que se estabelecem como um obstáculo para um ensino com maior efetividade, sendo que tais fatores estão atrelados não apenas à indisciplina, mas a incapacidade de um acompanhamento mais direto do professor de geografia em conjunto com a professora de apoio e os alunos devido ao curto tempo das aulas, o papel dos pais ao fazerem intervenções negativas ao não levar o aluno para a realização de uma consulta, ou no que diz respeito às ausências nas aulas regulares, assim como na sala de recursos, em que a questão do transporte também se constitui como um obstáculo para uma aprendizagem mais qualitativa.

\section{REFERÊNCIAS}

BRASIL. Constituição da República Federativa do Brasil, de 5 de outubro de 1988. Diário Oficial da República Federativa do Brasil, Brasília, 5 de outubro de 1988.

BRASIL. Diretrizes Nacionais para a Educação Especial na Educação Básica. Ministério da Educação; Brasília, 2001.

BRASIL. Secretaria de Educação Fundamental. Parâmetros curriculares nacionais: geografia / Secretaria de Educação Fundamental. - Brasília: MEC/ SEF, 1998.

BRASIL. Ministério da Educação. Base nacional comum curricular. Brasília, DF: MEC, 2015. Disponível em: http://basenacionalcomum.mec.gov.br/. Acesso em 04/11/2019.

HAGE, S. A. M. A Multissérie em pauta: para transgredir o Paradigma Seriado nas Escolas do Campo. $2009 . \quad$ Disponível em: https://faced.ufba.br/sites/faced.ufba.br/files/multisserie_pauta.pdf. Acesso em 02/10/2019.

HAGE, S. A. M. Transgressão do paradigma da (multi)seriação como referência para a construção da escola pública do campo. Educ. Soc., Campinas, v. 35, nº. 129, p. 1165-1182, out.-dez., 2014.

LOPES, S. L. Orgs. Práticas educativas na educação do campo: desafios e perspectivas na contemporaneidade. Boa Vista: Editora da UFRR, 2015. Disponível em: https://www.finom.edu.br/assets/uploads/cursos/categoriasdownloads/files/20.pdf. Acesso em 04/10/2019. 
MINAS GERAIS. Guia de Orientação da Educação Especial na rede estadual de ensino de Minas Gerais. Secretaria de Estado de Educação de Minas Gerais, versão 3, 2014. Disponível em: http://www.espacoprofessor.com/2017/02/guia-de-orientacao-da-educacaoespecial.html. Acesso em 11/11/2019.

PARENTE, C. M. D. Escolas Multisseriadas: a experiência internacional e reflexões para o caso brasileiro. Ensaio: aval. pol. públ. Educ., Rio de Janeiro, v.22, n. 82, p. 57-88, jan./mar. 2014.

RODRIGUES, C. L. Educação no meio rural: Um estudo sobre salas multisseriadas. Dissertação. Universidade Federal de Minas Gerais, 2009. Disponível em: https://repositorio.ufmg.br/handle/1843/FAEC-8MAHYM. Acesso em 02/10/2019.

SAMPAIO, A. A. M. Orgs. Ler o Mundo com as Mãos e Ouvir com os Olhos: Reflexões sobre o Ensino de Geografia em Tempos de Inclusão. Uberaba - MG, 2011.

SANTOS, R. S. Educação do campo: classes multisseriadas e seus desafios pedagógicos. $11^{\circ}$ enfope, $11^{\circ}$ fopie, $2017 . \quad$ Disponível https://www.google.com/url?sa=t\&rct=j\&q=\&esrc=s\&source=web\&cd=2\&ved=2ahUKEwi9t OjX9PblAhVUF7kGHUcdDFUQFjABegQIBhAC\&url=https\%3A\%2F\%2Feventos.set.edu.b r\%2Findex.php\%2Fenfope\%2Farticle\%2Fdownload\%2F5363\%601. Acesso em 01/10/2019.

SILVEIRA, R. A. M. Formação e "deformação" docente. In Ler o Mundo com as Mãos e Ouvir com os Olhos: Reflexões sobre o Ensino de Geografia em Tempos de Inclusão. Uberaba - MG, 2011.

ZEFERINO, V. M. A educação do campo e seus desafios. TCC. Universidade Federal do Paraná, 2014. Disponível em: https://acervodigital.ufpr.br/bitstream/ha20ZEFE\&isAllowed=y. Acesso em 04/10/2019. 